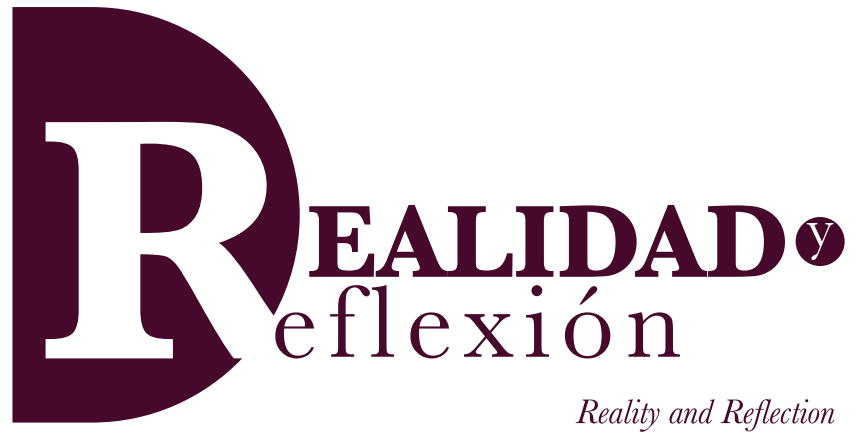

ISSN 1992-6510

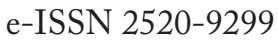

Año 20, N 52, San Salvador, El Salvador, Centroamérica. Revista Semestral Julio-Diciembre 2020

YEAR 20, $N^{\circ}$ 52, SAN SALVADOR, El SALVADOR, CENTRAL AMERICA. SEMESTRAL JOURNAL JULY-DECEMBER 2020

\title{
Impacto en la salud mental ocasionado por la pandemia del covid-19
}

Impact on mental bealth caused by the covid19 pandemic

Laura Chavarría de Cocar* lchavarria@ugb.edu.sv

Ana Yolanda Laínez

Mayra Ferrufino

José Félix Rojas

Fátima Ordóñez

Roció Araujo.

Investigadores Universidad Gerardo Barrios, E1 Salvador

*Autora principal

Recibido: 14 de julio de 2020 Aprobado: 31 de octubre de 2020 DOI: $10.5377 /$ ryr.v52i52.10759

(c) (i) (ㅇ) (O) 


\section{RESUMEN}

Este estudio aborda el impacto en la salud mental ocasionado por la pandemia del COVID-19, específicamente se identificaron características que definen los episodios depresivos y las reacciones emocionales que las personas han presentado en este contexto, con el fin de describir estas alteraciones que ponen en riesgo la salud mental de la población reconociendo que el ser humano debe tener un equilibrio y bienestar en la salud para que pueda ser productivo y fructífero a la sociedad. Se presentan aportes significativos a nivel de la región oriental de El Salvador, donde se verifico que independientemente la edad que las personas tengan, están presentando alteraciones en su salud mental, el $72 \%$ ha presentado desesperanza que es una característica de los episodios depresivos, el $7 \%$ refiere que desea morir antes que llegue el virus, aunque es un porcentaje mínimo pero se debe intervenir para prevenir riesgo de suicidio, entre las reacciones emocionales el $72 \%$ ha presento preocupación al momento de conocer el primer caso de COVID19 en el país, el 66\% miedo, el 54\% tristeza, por lo que se tienen que tomar las medidas pertinentes para prevenir riesgos patológicos.

Palabras claves: Episodios depresivos, reacciones emocionales, impacto en la salud mental, COVID-19.

\section{ABSTRACT}

This study addresses the mental health impact caused by the COVID-19 pandemic, specifically identifying characteristics that define depressive episodes and emotional reactions that people have presented in this context, in order to describe these alterations that put at risk the mental health of the population recognizing that the human being must have a balance and well-being in health in order to be productive and fruitful for society. Significant contributions have been made at the level of the eastern region of El Salvador, where it has been verified that, regardless of the age of the people concerned, they are presenting alterations in their mental health, $72 \%$ have presented hopelessness which is a characteristic of depressive episodes, $7 \%$ say they want to die before the virus arrives, although it is a minimal percentage but must be intervened to prevent risk of suicide, among emotional reactions $72 \%$ have presented concern at the time of knowing the first case of COVID-19 in the country, 66\% fear and 54\% sadness, so appropriate measures have to be taken to prevent pathological risks.

Key words: Depressive episodes, emotional reactions, impact on mental health, COVID-19. 


\section{Introducción}

La pandemia del COVID-19 puso el bienestar de los habitantes a nivel mundial en incertidumbre, incluyendo la salud mental, considerando las alteraciones en la vida cotidiana. La Organización Mundial de la Salud (OMS) define la salud mental como un estado de bienestar, en el cual el individuo consciente de sus propias capacidades puede afrontar las tenciones normales de la vida, puede trabajar de forma productiva y fructífera y es capaz de hacer una contribución a su comunidad.

A nivel mundial el virus ha cobrado miles de vidas, las redes sociales y los medios de comunicación se han encargaron de mantener la información al día y los oyentes o teleaudiencia se han dado la tarea de mantenerse al día del acontecer mundial y nacional esto ocasionando grados de estrés y ansiedad en algunos países tomaron medidas radicales para reducir el contagio de dicha enfermedad y la población ha tenido que hacer cambios en los estilos de vida viviendo tiempos inciertos (Escobar-Córdoba, 2020), porque día a día han aparecido más casos y más personas han perdido la vida a causa de este virus (Mundo, 2020).Cada ciudadano ha pensado a corto plazo, y se ha centrado en la salud de sus compañeros, amigos y familiares y en la eficacia o deficiencia del Sistema Nacional de Salud y la atención que cada persona infectada ha recibido.

Es por ello que es necesario contar con un estudio donde puedan ser implícitas aquellas alteraciones que por sus criterios de diagnóstico deben ser estudiadas entre ellas episodios depresivos y reacciones emocionales que alterar la salud mental de las personas y que deben ser tratadas oportunamente para no agravar los casos patológicos. Existen estudios que explican si habrá una alteración en la salud mental cuando hay epidemias o pandemias, por ello se vuelve importante contar con un documento real, conciso y preciso sobre los problemas reales que están sufriendo las personas con estos situaciones anormales como lo es el coronavirus (StucchiPortocarrero, 2017).

El COVID-19 ha dejado a su paso a nivel mundial cientos de fallecidos, el mapa mundial del coronavirus describe más de 10.970.429 millones de casos y más de 525.042 muertos en todo el mundo(Hopking, 2020), lo que supone también un desgaste mental para aquellas personas que suspendieron sus labores o perdieron por completo sus empleos, dejaron de asistir a sus centros de estudio, perdieron a un ser querido, tienen miedo a sufrir el contagio o las cuarentenas impuestas en los distintos países alterado de forma significativa su forma o estilo de vida.

Esta pandemia ha alterado la vida cotidiana de cada persona, y con ello trajo incertidumbre, ruina, presiones económicas, y aislamiento social. (Universidad de Chile, 2020). Quizás la preocupación más grande ha sido el tiempo de duración de la pandemia, y qué consecuencias traería en el futuro. El exceso de información, los rumores y la información errónea puede hacer que las personas se sientan sin control y que no tengan claro qué hacer. (MAYO CLINIC, 2020)

Esto lo convierte en un estudio idóneo y pertinente, pues es liderado por un equipo multidisciplinario en salud tanto física como mental, que a partir de sus conocimientos y 
experiencias han aportado posibles escenarios particulares según los criterios de diagnóstico, (American Psychiatric Association., 2016). Los objetivos fueron encaminados a identificar los episodios depresivos (distimia) y definir las reacciones emocionales ocasionadas por la pandemia del COVID-19. Es importante identificar y conocer estos problemas para tomar medidas de mitigación e identificar los grupos vulnerables, las futuras estrategias por implementar en el contexto actual, pudiendo ser replicadas y ajustadas en distintas instituciones y entidades que deseen contribuir a recuperar la salud mental de sus comunidades en particular.

Se desconocen estudios publicados sobre dicho tema en el país, pero si existen instituciones que están trabajando actualmente en temas relacionado, por lo que este estudio servirá como punto de partida para que las organizaciones gubernamentales y no gubernamentales del país puedan tomar decisiones oportunas y eficaces que puedan beneficiar a la población salvadoreña.

\section{Metodología}

El propósito de esta investigación fue conocer el impacto en la salud mental ocasionado por la pandemia del COVID-19, el enfoque fue cualicuantitativo, ya que se interpretaron los datos de las personas que participaron en el estudio y el tipo de muestreo aleatorio simple (Triola, 2004). Se aplicó la técnica de la encuesta utilizando el cuestionario online en QuestioPro, el cual consta de 2 sesiones. La primera parte del instrumento evalúa datos específicos de la persona, y la segunda parte se describen preguntas sobre las variables del estudio. El instrumento consta de 17 preguntas categorizadas, y se validó a través de la revisión de expertos para medir el nivel de confiabilidad y de aplicabilidad del mismo.

Alutilizar estas herramientas se pretendió obtener dos datos importantes que según los criterios de diagnóstico aplica para la situación actual, episodios depresivos y reacciones emocionales. (American Psychiatric Association., 2016)

Del tamaño de la población de 10,000 habitantes se tomó una muestra de 1,000 personas.

La muestra se seleccionó suponiendo normalidad en la población, se utilizó la fórmula que relaciona el Tamaño de muestra $(\mathrm{TM}) \operatorname{con} / \mathrm{Z}^{\wedge} 2=$ valor $Z$ para una normal con el nivel de confianza seleccionado, por ejemplo, para $95 \% Z^{\wedge} 2=1.96$ $/ \mathrm{p}$ = porcentaje que elige una opción, expresado como decimal (.5 usado por defecto) $/ \mathrm{c}=$ Intervalo de confianza, expresado en porcentaje. Se utilizó la calculadora de muestra del software de encuestas ( Creative Research Systems, 2012).

\section{Fórmula de tamaño de muestra}

Donde:

$Z$ = valor $Z$ (por ejemplo, 1.96 para un nivel de confianza del $95 \%), p=$ porcentaje que elige una opción, expresado como decimal (se necesita .5 para el tamaño de la muestra) $\mathrm{c}=$ intervalo de confianza, expresado como decimal (por ejemplo, $.04= \pm 4$ )

Obteniendo una muestra de 1,000 personas que participaron de forma aleatoria simple, donde los participantes del estudio fueron 1,037. Aumentando el número de la muestra dando un mejor intervalo de confianza. 
El análisis e interpretación de los datos cuantitativos se hizo por medio de tablas simples la que se presentan a continuación:

\begin{tabular}{l|l|c|c|c}
\hline \multirow{2}{*}{ No } & \multirow{2}{*}{ Items } & \multirow{2}{*}{ Opciones } & \multicolumn{2}{|c}{ Respuestas } \\
\cline { 3 - 4 } & & & Frecuencia & Porcentaje \\
\hline
\end{tabular}

Para representar los hallazgos principales se realizaron graficas lineales tipo fila, cada una con sus respectivos análisis e interpretación.

El análisis cualitativo se hizo con la elaboración de un mapa, elaborado con https://www. wordclouds.com/, donde se subido el texto, fue una pregunta opcional del cuestionario. Todas las palabras se visualizaron en la imagen, el tamaño de las palabras refleja las más frecuentes respondidas por la población participante, luego se hizo la interpretación de los datos dando conclusiones y recomendaciones pertinentes. Otros estudios han utilizado las nubes temáticas, estas estrategias permiten visualizar las palabras que las personas expresan de forma gráfica (Fernández, 2015) y se pueden utilizar en investigaciones sociales. (Milles MB, 2013)

\section{Resultados}

En este apartado se dieron a conocer los resultados del estudio las primeras 7 preguntas son datos generales de cada persona participante y luego, se evidencian las características de los episodios depresivos y las reacciones emocionales que la población está presentando en las últimas dos semanas (American Psychiatric Association., 2016) previo al llenado del cuestionario. Se encontró la opción de "No contesta" es cuando las personas no prefirieron contestar a la interrogante, la psicología explica este fenómeno como un periodo de negación a la realidad que se está enfrentando. (Roland Doron, 2008)

\section{Principales hallazgos cuantitativos}

Este enfoque cuantitativo permite medir, interpretar y analizar datos de los sujetos participantes en el estudio, este método se usa para ordenar secuencialmente y de forma objetiva los datos recolectados, que a continuación se representan por medio de gráficas, análisis e interpretaciones.

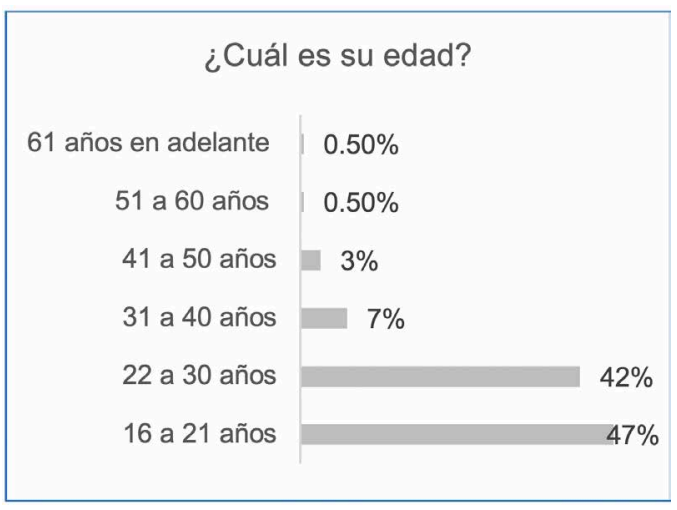

Ilustración 1: Gráfico que muestra las edades de los participantes en el estudio.

Análisis: Del 100\% de participantes encuestados, el $47 \%$ se encuentra entre las edades de 16 a 21 años; el $42 \%$ entre 22 a 30 años; el $7 \%$ entre 31 a 40 años; el 3\% entre 41 a 50 años; el $0.5 \%$ entre 51 a 60 años y el $0.5 \%$ de 61 años en adelante.

Interpretación: La mayoría de las personas participantes en el estudio están en etapa adolescentes y adulto joven, porque lo que son capaces de expresar alteraciones en las emociones o características que defina la salud mental. 


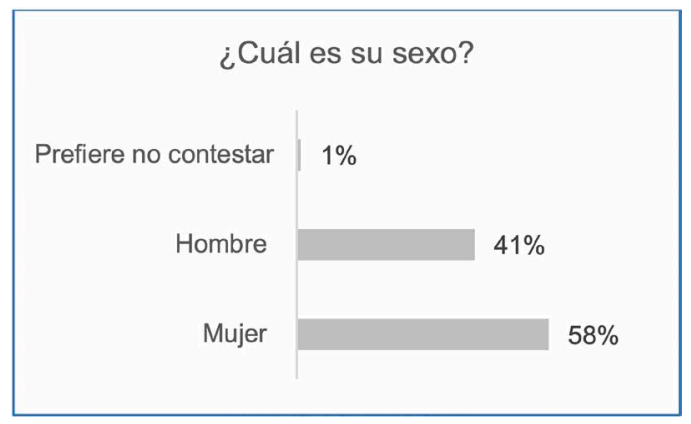

Ilustración 2: Gráfico que muestra el sexo de los participantes en el estudio.

Análisis: Del 100\% de participantes encuestados, el $58 \%$ son mujeres, el $41 \%$ son hombres y el $1 \%$ prefirió no contestar.

Interpretación: La mayoría de personas que participaron en el estudio son mujeres. Algunas mujeres en El Salvador cumplen roles en el hogar como ser madre, esposa, ama de casa, cuidar a los hijos/as, en la mayoría de casos todo ocurre entorno a ellas.

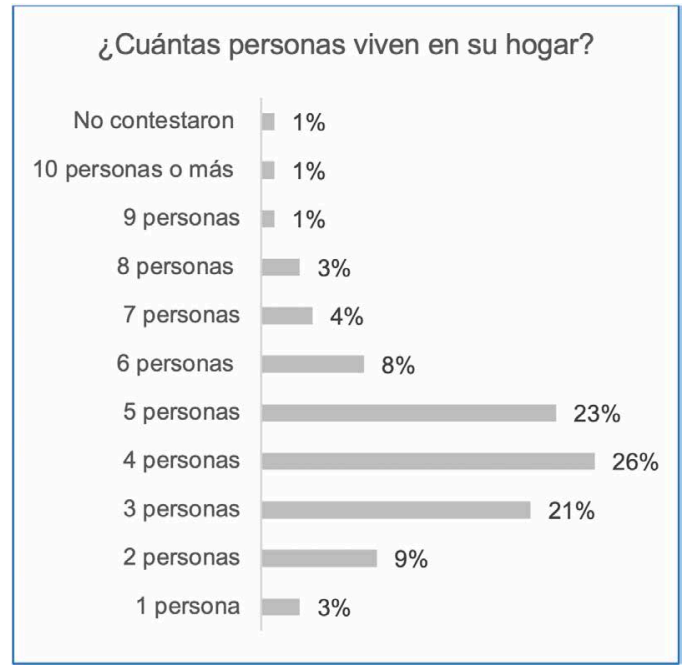

Ilustración 3: Gráfico que muestra el número de personas que viven con los participantes en el estudio.
Análisis: Del 100\% de participantes encuestados el 3\% vive solo con 1 persona, el $9 \%$ con 2 , el $21 \%$ con 3 , el $26 \%$ con 4 , el $23 \%$ con 5 , el $8 \%$ con 6 , el $4 \%$ con 7 , el $3 \%$ con 8 , el $1 \%$ entre 9 a 10 personas y el $1 \%$ prefirió no contestar.

Interpretación: los núcleos familiares se conforman en un promedio de 3 a 5 integrantes, por lo que es muy importante cubrir las necesidades básicas de todos los miembros de la familia ante la pandemia del COVID-19 y también es una fortaleza para las personas porque pueden sentirse emocionalmente apoyados.

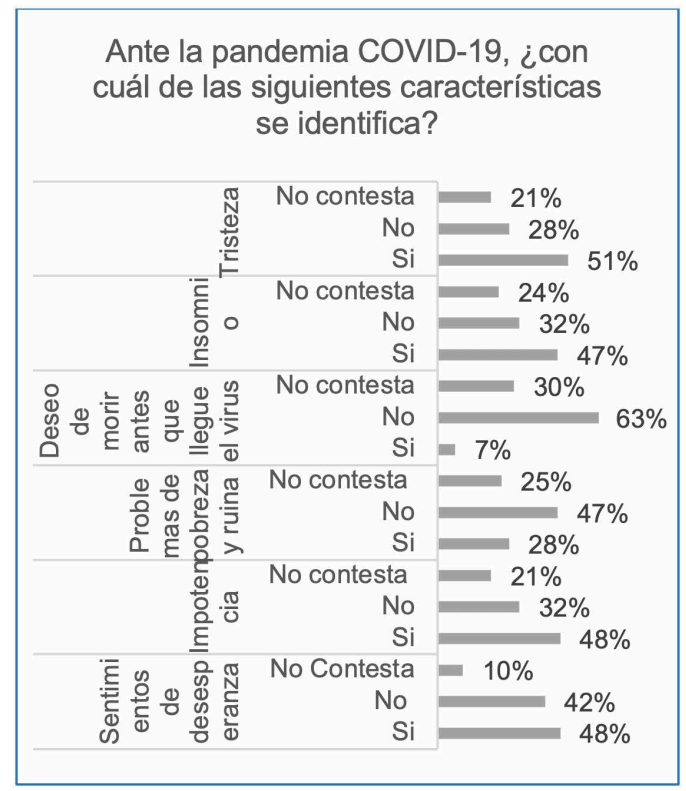

Ilustración 4: Gráfico que representa características de episodios depresivos ante la pandemia del COVID-19 de los participantes del estudio.

Análisis: Del 100\% de participantes encuestados, el $48 \%$ manifiesta sentimientos de desesperanza, mientras un $42 \%$ no y un $10 \%$ prefirió no contestar. En las características de impotencia el 48\% refiere que sí se identifica con ella, el $32 \%$ que no y el 
$21 \%$ prefieren no contestar. En la característica de problemas de pobreza y ruina el $28 \%$ afirma experimentarla, mientras el $47 \%$ no y el $25 \%$ prefirió no contestar. En la característica de deseos de morir antes que llegue el virus afirma el $7 \%$ que si lo ha pensado, el 63\% que no y el 30\% prefirieron no contestar. En la característica de insomnio el $47 \%$ asegura que si ha presentado insomnio, el $32 \%$ que no y el $24 \%$ prefirieron no contestar. En la característica de tristeza el 51\% refiere que sí se identifica el 28\% que no y el $21 \%$ prefiere no contestar.

Interpretación: La gráfica muestra resultados de sintomatología que podría indicar niveles de episodios depresivos,es evidentequeenlatotalidad de los participantes, existen manifestaciones de tener algún grado de afectación a nivel emocional, caracterizando la pandemia del COVID-19 con las manifestaciones siguientes: sentimiento de desesperanza, impotencia, tristeza, insomnio, problemas de pobreza y ruina, deseos de morir antes que llegue el virus, este último que debe ser intervenido para prevenir riesgo de suicidio.

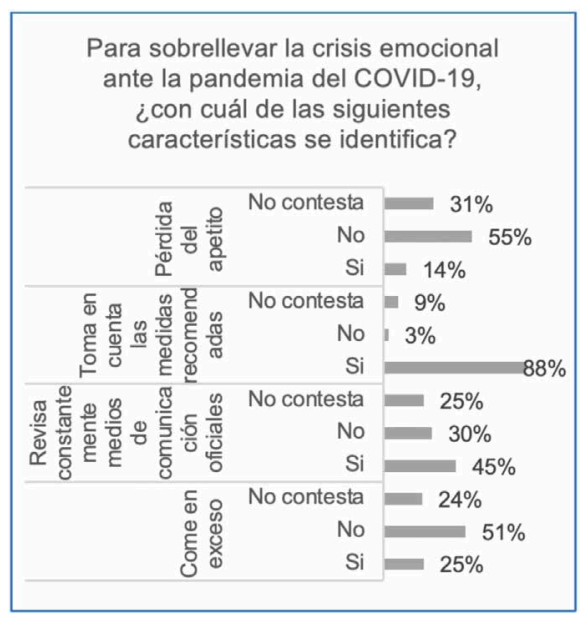

Ilustración 5: Gráfico que representa características que identifican como están sobrellevando la crisis emocional ante la pandemia las personas participantes del estudio.
Análisis: Del 100\% de participantes encuestados, el $25 \%$ afirma que comer en exceso es una de las características con las que se identifica para sobrellevar la crisis emocional, mientras el 51\% asegura que no y el $24 \%$ prefiere no contestar.

Otra característica es el revisar constantemente los medios de comunicación oficiales, pues el $45 \%$ afirma sentirse identificado, un $30 \%$ no y un $25 \%$ prefiere no contestar. En lo que ha tomar en cuenta las medidas recomendadas para prevenir el COVID-19 se refiere, el $88 \%$ asegura tomarlas en cuenta, mientras un $3 \%$, no y el $9 \%$ prefiere no contestar.

Po otro lado referente a la pérdida del apetito, el $14 \%$ afirma que sí ha sufrido de pérdida del apetito, el $55 \%$ no y el $31 \%$ prefiere no contestar.

Interpretación: La mayoría la población refiere que revisa frecuentemente los medios de comunicación oficiales para conocer sobre la pandemia y también refieren que están tomando las recomendadas para prevenir el COVID-19. Es notable también la presencia de problemas en la conducta alimenticia como comer en exceso y pérdida del apetito, a estos afectados es a quienes se les debe proporcionar mensajes de autocuidado de la salud y la solidaridad con su grupo y la comunidad; como también socializar técnicas para el manejo de la ansiedad. 


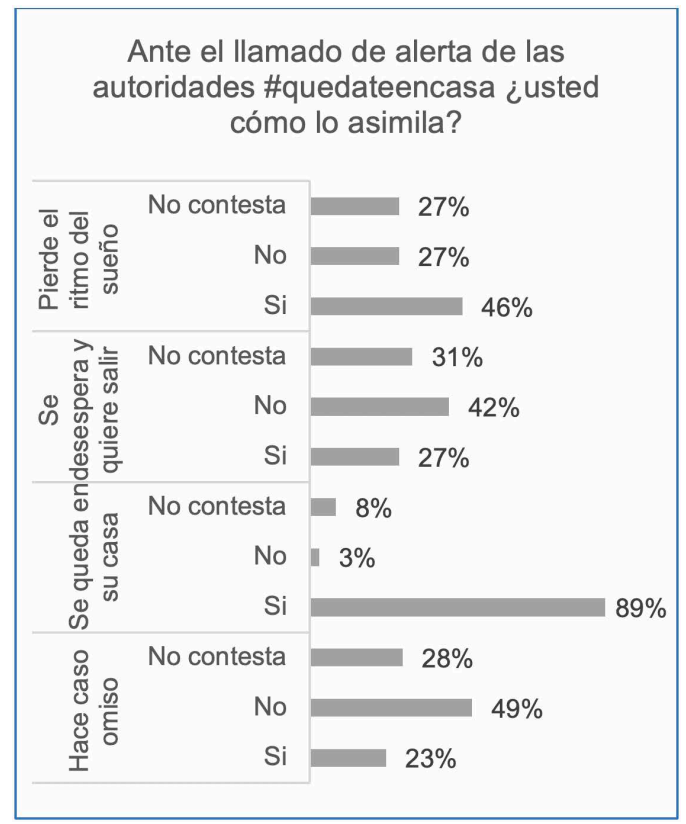

Ilustración 6: Gráfico que representa como asimilan el llamado de las autoridades \#quédateencasa de los participantes del estudio.

Análisis: Del 100\% de participantes encuestados, el 23\% afirma que hace caso omiso a la indicación de las autoridades de quedarse en casa, un 49\% no y el $28 \%$ prefiere no contestar. En lo que ha quedarse en casa se refiere, el 89\% afirma que sílo hace, el 3\% que no y el $8 \%$ prefiere no contestar. En la característica de desesperarse y querer salir de su casa el 27\% manifiesta que sí, el $42 \%$ que no y el $31 \%$ prefiere no contestar. En la característica donde se evaluó la pérdida del ritmo del sueño el $46 \%$ refiere que sí lo ha manifestado, el $27 \%$ que no y el $27 \%$ prefieren no contestar.

Interpretación: La grafica de resultados indica que las personas están atendiendo el llamado de las autoridades de \#QuédateEnCasa como medida preventiva para contener el contagio masivo del COVID-19; provocando diversidad de trastornos psicológicos entre los que se pueden mencionar problemas del sueño y la vigilia.

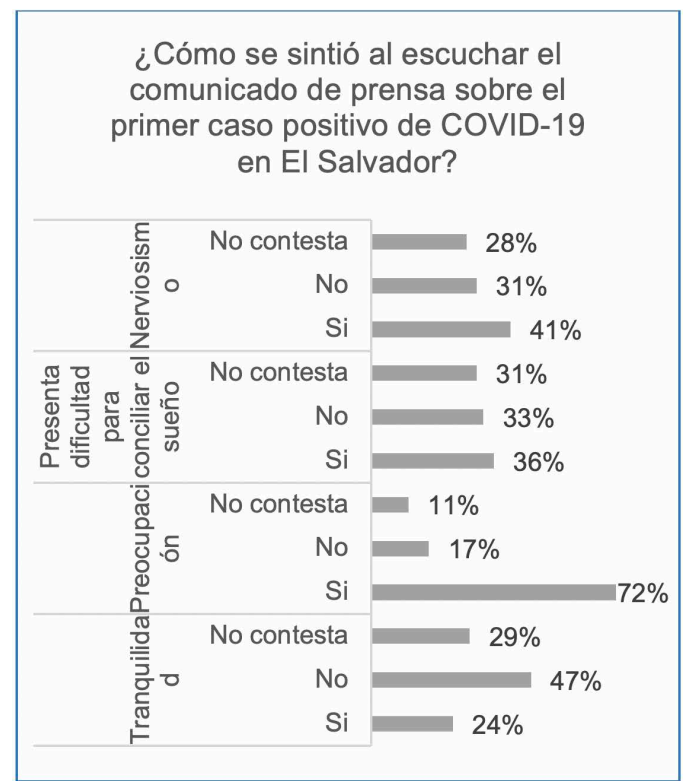

Ilustración 7: Gráfico que representa como se sintió al escuchar el primer caso de COVID19 en El Salvador de los participantes del estudio.

Análisis: Referente a qué sentimientos experimentó al escuchar el comunicado de prensa sobre el primer caso positivo de COVID-19 en El Salvador, del $100 \%$ de participantes encuestados, el 24\% afirmó haber experimentado tranquilidad, mientras el $47 \%$ difiere y el $29 \%$ prefirió no contestar. En la característica de preocupación el $72 \%$ refiere que si lo manifestó, el 17\% que no y el 11\% prefirieron no contestar. En la característica de dificultad para conciliar el sueño el 36\% refiere que sí presentó problemas para dormir, el 33\% que no y el 31\% prefirieron no contestar. $\mathrm{El}$ nerviosismo fue la última característica explorada, en ello el 41\% afirmó que sí lo experimentó, el $31 \%$ que no y $28 \%$ prefirieron no contestar. 
Interpretación: La población participante reconoce que a raíz de la noticia del primer caso de COVID-19 en El Salvador presentaron manifestaciones de intranquilidad, preocupación, dificultad para conciliar el sueño acompañado de nerviosismo. Lo que puede incrementar con el progreso de la situación de contagio en el país y por ello las personas deben recibir atención de higiene mental.

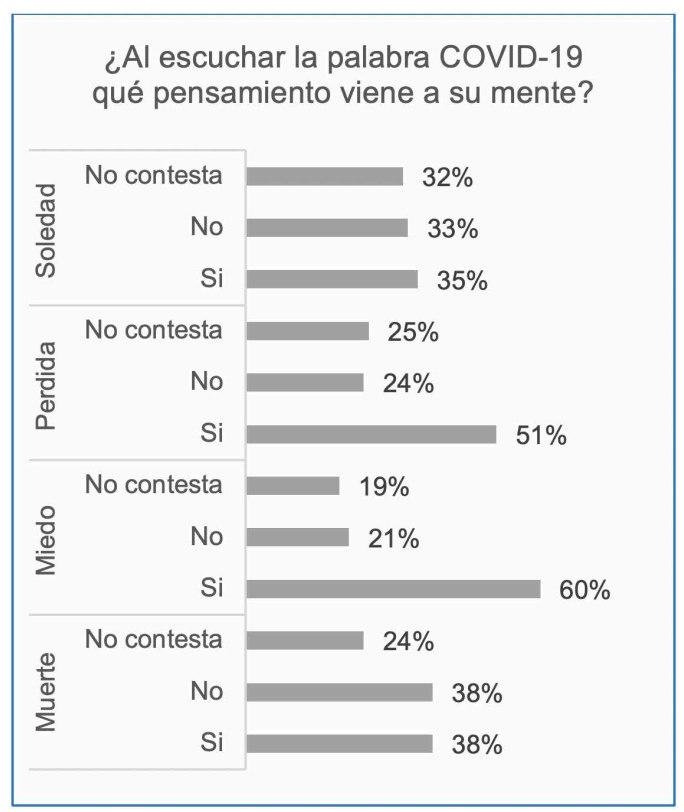

Ilustración 8: Gráfico que representa que pensamiento viene a su mente cuando escucha la palabra COVID-19 de los participantes del estudio.

Análisis: Con relación al pensamiento que llega a la mente de las personas al escuchar la palabra COVID-19 según el cuestionario, un $38 \%$ afirma relacionarla con muerte, un $38 \%$ no y el $24 \%$ prefirió no contestar. Respecto al miedo, un $60 \%$ afirma que sí lo asocia, el $21 \%$ que no y el 19\% prefirieron no contestar. Con pérdida lo asocia un $51 \%$, un $24 \%$ no y el $24 \%$ prefirió no contestar. Referente a la soledad el 35\% aseguró relacionarla con COVID-19, un 33\% no y el $32 \%$ prefirió no contestar.

Interpretación: La población del estudio asocia el COVID-19 principalmente con el miedo y las pérdidas, en menos frecuencia se encontraron pensamientos de soledad y muerte. Independiente del porcentaje obtenido en los resultados, se demuestra que en todos los aspectos explorados hay frecuencia que denota la existencia de pensamiento que interfiere la salud mental.

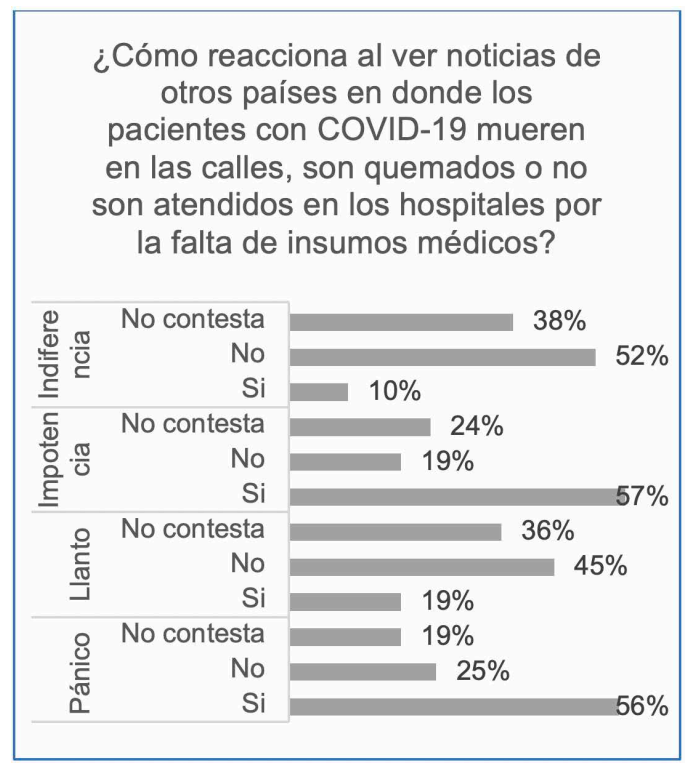

Ilustración 9: Gráfico que representa algunas reacciones de los participantes del estudio al ver noticias de otros países que tienen pacientes con COVID-19 y que mueren en las calles.

Análisis: En este apartado se exploraron las reacciones de los encuestados al ver noticias internacionales referentes al COVID-19. Del $100 \%$ de las personas, el $56 \%$ afirma que manifestó pánico, un $25 \%$ no y el $19 \%$ prefirió no contestar. En la característica de llanto, el 19\% afirmó haberlo manifestado, el $45 \%$ no y el $36 \%$ prefirió no contestar. En lo que a la impotencia se refiere, 
el $57 \%$ afirma sufrirla cada vez que se informa, un 19\% difiere y el 24\% prefirió no contestar. En la última característica que es la indiferencia el 10\% afirma que sí es indiferente ante las noticias, un $52 \%$ no y el $38 \%$ prefirió no contestar.

Interpretación: La población en estudio reconoce presentar reacciones emocionales en este orden en mayor frecuencia mencionan el pánico,impotencia y no pueden ser indiferentes al escuchar las noticias internacionales, con menor frecuencia existe la presencia del llanto. Estas respuestas emocionales podrían exacerbarse con situaciones parecidas en el país, por lo que es necesario compartir con la población actividades que fortalezcan la resiliencia.

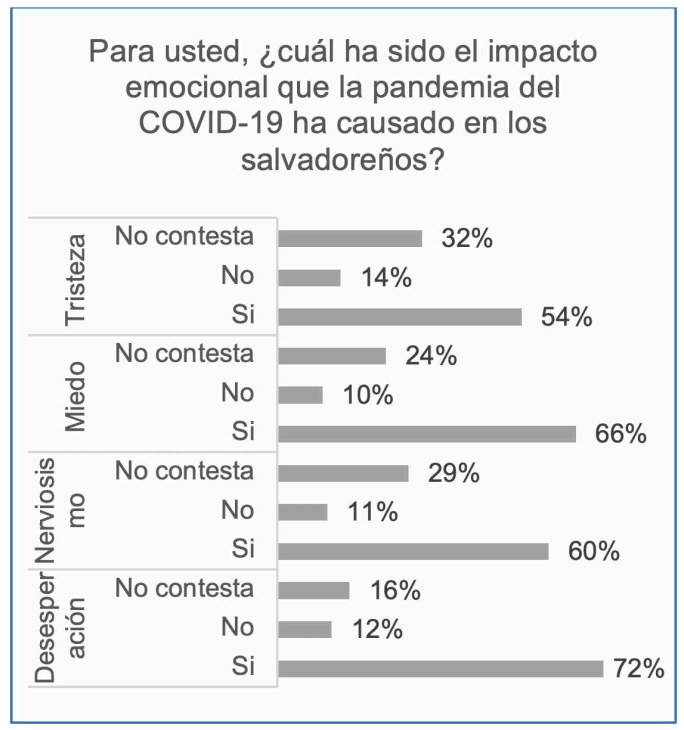

Ilustración 10: Gráfico que representa el impacto emocional que la pandemia del COVID-19 ha causado en los salvadoreños referencia de los participantes del estudio.

Análisis: Del 100\% de participantes encuestados, el 72\% comenta que el COVID-19 ha generado desesperación en los salvadoreños, mientras un $12 \%$ difiere y un $16 \%$ prefirió no contestar. Referente a la característica de nerviosismo el $60 \%$ refiere que los salvadoreños sí han manifestado esta reacción, el 11\% no y el 29\% prefirió no contestar. El miedo es otra característica que se exploró y el 66\% afirma que los salvadoreños han presentado miedo, el 10\% no y el $24 \%$ prefirió no contestar, mientras que referente a la tristeza, el 54\% aseguró que los salvadoreños si la han experimentado a causa del COVID-19, un $14 \%$ considera que no y el $32 \%$ prefirió no contestar.

Interpretación: Toda la población en su mayor porcentaje considera que la pandemia causa desesperación, nerviosismo, miedo y tristeza.Aunque es una interrogante indirecta, pero se pueden estar proyectando estar reacciones a nivel personal o familiar por lo que se deben dar las intervenciones acertadas para disminuir estas alteraciones.

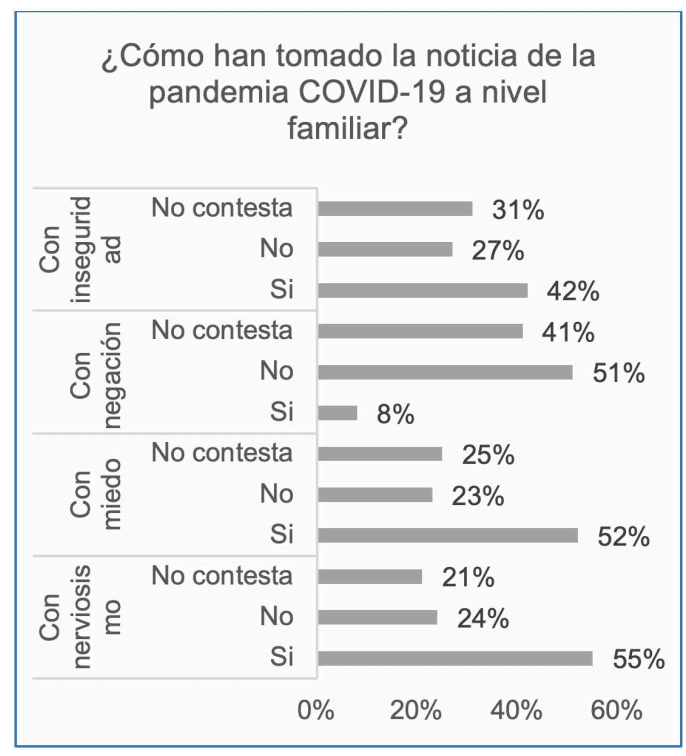

Ilustración 11: Gráfico que representa como han tomado la noticia de la pandemia a nivel familiar, los participantes del estudio. 
Análisis: Del 100\% de participantes encuestados, el 55\% afirmó que a nivel familiar la pandemia del COVID-19 ha generado nerviosismo, un $24 \%$ considera que no y el $21 \%$ prefirió no contestar. Referente al miedo, el 52\% afirmó que si lo manifiestan, un $23 \%$ no y el $25 \%$ prefirió no contestar. Respecto a la negación, el 8\% refiere haberla experimentado, el $51 \%$ no y el $41 \%$ prefirió no contestar. Y en lo que a inseguridad se refiere, el $41 \%$ aseguró que a nivel familiar esta característica sí ha tenido presencia, un $27 \%$ difiere y el 31\% prefirió no contestar.

Interpretación: La gráfica indica que las familias asimilan la noticia del COVID-19 con miedo y nerviosismo posiblemente porque día a día ha incrementado el número de muertes a nivel mundial a causa de este virus, además porque posiblemente tienen familiares en otros países donde el virus se ha expandido con mayor rapidez y ha dejado miles de fallecidos entre ellos miembros de su familia.

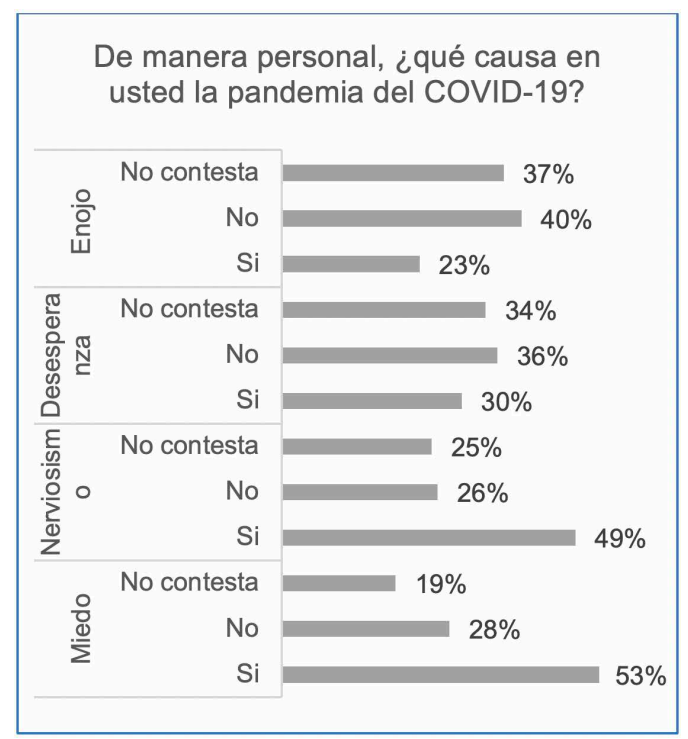

Ilustración 12: Grafico que representa que ha causad la pandemia del COVID19 de manera personal de los participantes del estudio.
Análisis: De forma personal, del 100\% de los encuestados, un 53\% afirmó sentir miedo, un $28 \%$ no y el $19 \%$ prefirió no contestar. Relacionado al nerviosismo, el 49\% aseveró haberlo manifestado, un 26\% difiere y el $25 \%$ prefirió no contestar. Otra reacción evaluada fue la desesperanza, donde el 30\% afirmó haberla manifestado, el $36 \%$ no y el $34 \%$ prefirió no contestar. Entre la última reacción está el enojo, asegurando experimentarlo un $23 \%$, un $40 \%$ no y el $37 \%$ prefirió no contestar.

Interpretación: Al indagar lo que le causa el COVID-19, se observa en la gráfica que los porcentajes mayores corresponden que la reacción emocional es miedo, nerviosismo, desesperanza y en menor frecuencia enojo. Reacciones emocionales normales esperada en eventos como este, pero que al no ser intervenidos oportunamente puede desencadenar no solo episodios, o convertirse trastornos emocionales y alteraciones psiquiátricas.

\section{Principales hallazgos cualitativos}

El enfoque cualitativo representa el análisis y la interpretación de datos que se pueda comprender la realidad de forma subjetiva, tal como las personas lo escriben o lo caracterizan, es la forma de obtener la verdad de cómo piensan los sujetos quienes dieron la información y actúan en función a su pensamiento e interpretación de la realidad. En el cuestionario se indicó una pregunta que su respuesta era opcional que decía: ¿Cómo se ha sentido durante este periodo de pandemia del COVID-19? A continuación se representa un mapa con las palabras que tuvieron frecuencia por más de 4 veces en las respuestas, entre más grande sea la palabra indica que fue más veces mencionada. 


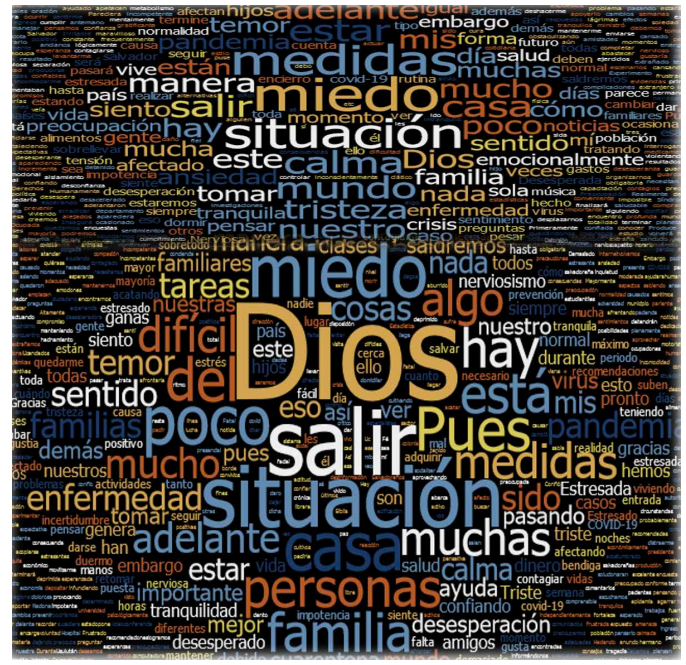

Ilustración 13: Este mapa representa las palabras que las personas participantes del estudio escribieron en la pregunta opcional. Fuente: Datos del cuestionario

\section{Interpretación:}

Se observa la presencia de términos que denotan la amenaza de perder el bienestar emocional como: miedo, dificultad, enfermedad, negativismo y desesperanza se infiere que con los términos neutrales compensan la situación generada por la pandemia del COVID-19. Las frases positivas se encaminan a identificar recursos emocionales existentes en su entorno religioso, académico, laboral, familiar, comunitario, de donde se obtiene las capacidades resilientes para abordar la adversidad.

\section{Discusión}

La salud mental es parte fundamental para el equilibrio del ser humano y esto permite que pueda ser productivo y fructífero contribuyendo de forma significativa a la sociedad y en las circunstancias actuales de la pandemia del COVID-19 se puede evidenciar según datos del estudio que estos resultados identificaron características de los episodios depresivos y reacciones emocionales que son indicadores de alteraciones en la salud mental.

Es importante notar que independientemente de la edad de las personas en estudio, manifiestan tener algún grado de afectación emocional, entre ellas sentimientos que caracterizan los episodios depresivos como: desesperanza, nerviosismo, impotencia, tristeza, pérdida del ritmo del sueño o insomnio, soledad, llanto, problemas de pobreza y ruina, deseos de morir antes que llegue el virus. Este último elemento aunque mínimo es importante tomarlo en cuenta para intervenir y disminuir el riesgo de suicidio según la Organización Mundial por la Salud pide cuidar la salud mental ante un posible aumento de suicidios por el coronavirus, (Noticias ONU, 2020), existe un estudio con nombre: Protección de la salud mental y atención psicosocial en situaciones de epidemias donde se pueden evidenciar la similitud de alguna característica en la población refiriendo que las epidemias son emergencias sanitarias de gran impacto, en las que se ve amenazada la vida de muchas personas y pueden causar cantidades significativas de enfermos y muertos; el temor al contagio agrava la situación existente. Por lo general, quedan amenazadas la seguridad y funcionamiento normal de la comunidad. E1 impacto psicosocial puede exceder la capacidad de manejo de la población afectada; se estima un incremento de la incidencia de trastornos mentales y manifestaciones emocionales, de acuerdo a la magnitud de la epidemia y el grado de vulnerabilidad de la población. (Organización Panamericana de la Salud, 2016) 
La población en estudio manifiesta que en la familia y a nivel personal han reaccionado a la pandemia del COVID-19 con las características de nerviosismo, miedo, negación, inseguridad, desesperanza, enojo. Estas características pueden manifestarse con violencia intrafamiliar o a la niñez, por lo que deben ser tratadas con higiene mental o terapias que puedan disminuir sus alteraciones y mejorar su bienestar, reconociendo que el ser humano tiene una concepción holística o integral. Se conocen de instituciones como el Ministerio de Salud ha implementado la asistencia psicológica en línea, también se conocer de organismos internacionales que han creado plataformas de información para el público y para el personal de salud.

La población en estudio manifiesta estar tomando en cuenta las medidas de prevención y seguridad para el COVID-19, en su mayoría consideran importante no salir de casa y refieren que asimila de forma positiva que los medios oficiales informen a la población sobre el avance y estadísticas sobre la pandemia, así mismo afirma confiar en el Sistema de Salud Pública al realizarse la prueba, actualmente se puede evidenciar la negación y el temor que las personas tiene al solicitar atención medica en las diferentes Unidades Comunitarias de Salud Familiar u Hospitales, sintiendo miedo al contagio buscando la asistencia cuando los síntomas agravan y eso empeora el cuadro clínico de la enfermedad, por otra parte manifiestan tener fe, que si en algún momento determinado dieran positivo al resultado, no se angustiarían, sino al contrario confiarían plenamente en Dios, culturalmente los salvadoreños son religioso o practican actividades espirituales que les fortalece su fe, en el país se han visto diferentes iniciativas para fortalecer esta esfera, el presidente Bukele llama a los «creyentes» a orar por el país. (Periodico Digital , 2020).

Este tipo de estudios son importantes para encontrar soluciones reales a los problemas actuales que azotan a los salvadoreños, añadiendo que estas investigaciones son necesarias y claves para la toma de decisiones. "A través de la función investigativa buscamos propiciar el pensamiento crítico, estudiar y analizar información de las condiciones del entorno sobre temas que interesan y preocupan a la sociedad, a fin de que permitan abonar a la solución de problemáticas actuales" expresó Dra. Diana Jiménez, Directora de la Unidad de Investigación.

A través de este tipo de investigaciones, la Universidad Gerardo Barrios pretende brindar información seria, rigurosa y responsable que sirva de soporte para la toma decisiones, para el caso particular, que las diferentes institucionales y entidades gubernamentales $y$ no gubernamentales del país, puedan fortalecer programas orientados a la atención de la salud mental de los salvadoreños, que junto a la salud física y social logran el bienestar completo que el ser humano necesita según la Organización Mundial de la Salud, reconociendo que el ser humano debe estar saludable en su salud mental para ser productivo y fructífero para la reactivación económica del país.

\section{Recomendaciones}

Las recomendaciones son valiosa y van dirigidas a los grupos poblacionales a nivel institucional o colectiva en entornos laborales y a nivel familiar, están proporcionadas a la luz de los resultados 
del estudio son acciones específicas en base a las alteraciones de la salud mental de la población siendo pertinentes a nuestras condiciones $y$ contexto ya que partieron de datos reales, a continuación se describen:

\section{- A nivel institucional o colectiva con entornos laborales.}

En cada institución deben contar con psicólogos/ as profesionales que puedan dar cobertura a la población que labore en dicha institución, y este personal debe capacitar a personas con perfiles idóneos para que puedan brindar una atención en crisis, mientras son atendidos por profesionales que puedan dar una intervención adecuada al problema. Reflexionar con los grupos sobre las alteraciones en la salud mental y cuando se evidencia una característica o sintomatología, las personas puedan solicitar apoyo psicológico a personal capacitado para su atención oportuna y eficaz.

Como instituciones crear programas de capacitación o talleres que lleven a la práctica de actividades de higiene mental, prevención de suicidios, atención de primeros auxilios psicológicos, también es importante la ayuda entre compañeros de trabajo identificando a personas con problemas en su salud mental y refiriéndolos al personal capacitado para que reciba una atención que mejore su bienestar y motive a practicar estas intervenciones que beneficiaran su salud.

Diseñar estrategias de comunicación para proporcionar información real, precisa $y$ concreta sobre las actuaciones a seguir cuando se identifique una alteración en su salud mental y brindar acompañamiento en las estrategias de información masiva.

\section{- A nivel familiar}

Según los datos de los participantes en el estudio en cada familia viven entre 3 a 5 personas esto es una oportunidad para que puedan realizar la práctica de la higiene mental, ya que es un mecanismo de prevención para el malestar psicológico, que consiste en un conjunto de actividades que una persona puede hacer dentro del hogar de forma colectiva o individual que desarrollara un equilibrio con su entorno, entre estas actividades esta: La terapia de risa antes de dormir, pensamientos positivos, masajes, respiración profunda y consciente, motivar a la resiliencia que es la capacidad que el ser humano tiene para afrontar situaciones adversas de la vida.

Es importante reconocer esta crisis como una oportunidad de crecimiento y desarrollo familiar. Se propone fortalecer áreas en entorno de familia como la autoestima de cada miembro del hogar eso permitirá conocer las fortalezas y debilidades, aceptarlas y asumirlas para afrontar las situaciones adversas y acontecimientos actuales como pandemia del COVID-19 que ha venido a alterar de forma significativa los estilos de vida de la población.

\section{Referencias}

Creative Research Systems. (2012). calculadora de muestra del software de encuestas. Obtenido de https://www.surveysystem.com/sscalc.htm

American Psychiatric Association. (2016). Manual diagnóstico y estadistico de los trastornos mentales. Arlington: AMERICAN PSYCHIATRIC ASSOCIATION . 
Centro para el control y prevención de enfermedades. (12 de junio de 2020). Enfermedad del coronavirus 2019 (COVID-19). Obtenido de https://espanol.cdc.gov/coronavirus/2019-ncov/ daily-life-coping/managing-stress-anxiety.html

Centro para el Control y Prevención de Enfermedades. (30 de abril de 2020). Estrés y cómo sobrellevarlo. Obtenido de https://espanol. cdc.gov/coronavirus/2019-ncov/daily-lifecoping/managing-stress-anxiety.html

Diario Concepción . (23 de Marzo de 2020). Cómo cuidar la salud mental en tiempos de pandemia por el Covid-19. Obtenido de https:// www.diarioconcepcion.cl/ciudad/2020/03/23/ como-cuidar-la-salud-mental-en-tiempos-depandemia-por-el-covid-19.html

Escobar-Córdoba,F.(2020).CONSECUENCIAS DE LA PANDEMIA COVID-19 EN LA SALUD. Obtenido de file://C:/Users/Denis/ Downloads/303-Preprint\%20Text-344-1-1020200502.pdf

Fernández, C. H. (2015). Nuevos recursos para la investigación. Redalyc.org, 1-20.

Hopking, J. (02 de julio de 2020). COVID-19 Dashboard by the Center for Systems Science and Engineering (CSSE) at Johns Hopkins University (JHU). Obtenido de https://coronavirus.jhu. edu/map.html

La Opinión. (5 de Abril de 2020). Las pandemias más letales que azotaron a la humanidad. Obtenido de https://www.laopinion.com.co/mundo/ las-pandemias-mas-letales-que-azotaron-lahumanidad-194526\#OP
MAYO CLINIC. (5 de Abril de 2020). COVID19YTU SaludMental. Obtenido de tps:// www.mayoclinic.org/es-es/diseases-conditions/ coronavirus/in-depth/mental-health-covid-19/ art-20482731

Milles MB,H.A. (2013). Qualitative data analysis: an expanded sourcebook. Obtenido de https:// vivauniversity.files.word press.com/2013/11/ milesandhuberman1994.pdf

Ministerio de Salud de El Salvador. (8 de octubre de 2018). Política nacional de salud mental. Obtenido de http://asp.salud.gob.sv/regulacion/ pdf/politicas/politicanacionalsaludmental2018.pdf

MINISTERIO DE SALUD DE EL SALVADOR. (08 de octubre de 2018). Politica Nacional de Salud Mental. Obtenido de http:// asp.salud.gob.sv/regulacion/pdf/politicas/ politicanacionalsaludmental2018.pdf

Mundo, N. (29 de junio de 2020). Coronavirus: el mapa que muestra el número de infectados y muertos en el mundo por covid-19. Coronavirus mapeado, págs. https://www.bbc.com/mundo/ noticias-51705060.

Noticias ONU. (14 de mayo de 2020). Ante un posible aumento de los suicidios por el coronavirus, la ONU pide tomar medidas para cuidar la salud mental. Obtenido de https://news.un.org/es/ story/2020/05/1474312

Organización Mundial para la Salud. (3 de Abril de 2020). CORONAVIRUS (COVID19). Obtenido de https://www.who.int/es

Organización Panamericana de la Salud. (2016). 
Protección de la Salud Mental en situaciones de epidemia. Obtenido de https://www.paho.org/ $\mathrm{hq} /$ dmdocuments/2009/Pandemia\%20de $\% 20$ influenza\%20y\%20Salud\%20mental\%20Esp.pdf

Pérez, J. R. (2020). Efectos psicologicos ante el COVID19. Periodismo, Ciencia y Tecnologia.

Periodico Digital.(22 demayo de2020).Tiemposde ser solidario. Obtenido de http://www.102nueve. com/2020/05/22/nayib-bukele-decreta-estedomingo-24-de-mayo-como-dia-nacionalde-oracion/\#: : text=E1\%20presidente $\% 20$ de $\% 201$ a $\% 20$ rep \% C 3\%B Ablica, 1a \% 20 madrugada\%20de\%20este\%20viernes.

QuestionPro. (2020). Calculadora de muestra. Obtenido de https://www.questionpro.com/es/ calculadora-de-muestra.html

Roland Doron, F. P. (2008). Diccionario Akal de Psicología. Madrid: Edicciones Akal.

Stucchi-Portocarrero, S. (2017). ¿Realmente existe una "epidemia de. Scielo/Peru.

Triola, M. F. (2004). Introducción a la Estadistica. México: Pearson Educación.
Universidad de Chile. (3 de abril de 2020). Las transformaciones sociales en la vida cotidiana que trae consigo la pandemia. Obtenido de https://www.uchile.cl/noticias/162321/lastransformaciones-sociales-del-coronavirus-enla-vida-cotidiana

Universidad de Chile. (07 de Abril de 2020). SALUD MENTAL EN SITUACIÓN DE PANDEMLA. Obtenido de file:///C:/Users/ Denis/Downloads/salud\%20menta1\%20 en $\% 20$ situacion $\% 20 \mathrm{de} \% 20$ pandemia $\% 20$ documento $\% 20$ para $\% 20$ mesa $\% 20$ social $\% 20$ covid\%2019.pdf

Velásquez, D. J. (10 de Marzo de 2020). Impacto de la COVID-19 en la salud mental. Obtenido de https://espanol.medscape.com/ verarticulo/5905131 